\title{
Timmermann's New Paradox of Hedonism: Neither New nor Paradoxical
}

\section{FRED FELDMAN}

1. Hedonism has been criticized over the years in a variety of ways. Some of these criticisms turn on alleged 'paradoxes of hedonism'. In a recent paper Jens Timmermann presents what he claims to be a novel and 'deeper paradox of hedonism that threatens alike all varieties of the thesis that pleasure is the good'. (2005: 144)

The core of Timmermann's argument is this: if hedonism were true, more pleasure would always be better; yet

...there can be cases in which we reject pleasure because there is too much of it. Sometimes we decide that pleasure is bad, or not worth having, not because of an extrinsic factor like moral, aesthetic etc. constraints but rather because one is experiencing enough pleasure to the point that more would in itself be undesirable. (2005: 144)

I have three main claims. First, Timmermann in fact presents a couple of different arguments against hedonism. One of these is apparently based on a confusion of psychological hedonism and normative hedonism. That argument is far less interesting than another, with which it is intertwined in the paper. Second, there is nothing new about Timmermann's alleged paradox. It has been discussed in the literature at least since 1988. ${ }^{1}$ Third, if we accept any version of the currently dominant view about the nature of sensory pleasure, the 'paradox' is unproblematic.

2. One line of argument in Timmermann's paper appears in several passages, including this one:

The new paradox presents the hedonist with a much more serious difficulty. It is argued that we occasionally reject additional pleasure itself, not for any contingent side effects but simply for what it is. This hedonists of any persuasion cannot admit. If human beings inevitably seek to maximize their own pleasure, why do they on occasion, when offered more, say that they have enough? (2005: 145)

The argument of this passage is clear: if hedonism were true, we all would always seek to maximize our own pleasure. But we don't: sometimes human beings reject additional pleasure. Therefore, hedonism ('of any persuasion') is false.

But the argument is also clearly confused. The distinction between ethical hedonism ('pleasure is the good') and psychological hedonism ('we are always ultimately motivated by a desire to maximize our own pleasure') has been familiar to students of moral philosophy since the time of Bentham. A defender of psychological hedonism might be troubled by the fact that 'we occasionally reject additional pleasure itself' but no defender of ethical hedonism needs to be troubled. Ethical hedonism -- the thesis that pleasure is the good -- does not imply anything about what people in fact seek or reject.

\footnotetext{
${ }^{1}$ I cite and discuss some of the relevant passages in the footnotes that follow.
} 
Thus, Timmermann is wide of the mark when he says that 'hedonists of any persuasion cannot admit' that 'we occasionally reject additional pleasure'. Ethical hedonists can (and do) admit this all the time.

3. A more interesting line of argument is suggested by other passages. In one of these passages, Timmermann says:

If we ought to promote pleasure as the good either in ourselves or in everyone, why is there a point at which a further increase in pleasure becomes undesirable? You cannot have too much of a good thing, let alone the good; but you can have too much pleasure. Ergo, pleasure and the human good are not identical. (2005: 145)

The target of this argument is ethical hedonism. The reasoning seems to be this: if ethical hedonism were true, increases in pleasure would always be better in themselves for the ones who experience them. But sometimes further increases in pleasure are not better in themselves for the ones who experience them. They don't make our lives better. They may even be undesirable. Therefore, ethical hedonism is not true.

Timmermann illustrates his case by appeal to several examples: 'strong sensual stimulation ...: intense food, being tickled, sexual pleasure. In these cases, the pleasure on offer, beyond a certain point, simply exceeds the limit of what we can bear.' (2005: 144) Consider some sensual pleasure. Imagine that the pleasurable sensations become more and more intense. They may be more enjoyable. Imagine that they become even more intense. They may start to be less enjoyable. If carried to extremes, they may become unpleasant. This sort of thing can happen, and when it happens it does not mark an improvement. That is the 'new paradox of hedonism'.

Timmermann is careful to distinguish his objection from a weaker objection that does not present much of a challenge to the hedonist. This weaker objection focuses on cases in which we have become bored with, or jaded by a type of sensation that is usually pleasurable.(2005: 145) In such cases, Timmerman says, the "activity" no longer gives us pleasure, or gives us less pleasure than some other option. This sort of case does not conflict with ethical hedonism, since in such cases we are not rejecting additional pleasure. We are rejecting some "activity" or sensation because it "has ceased to afford us pleasure'.(2005: 145) The sort of case that presents a problem for ethical hedonism arises, Timmerman says, when further increases in pleasure itself become undesirable.

To see why the argument goes wrong, we need to reflect a bit on the nature of pleasure and we need especially to be clear about what we mean when we speak of an "increase" in pleasure.

4. In an earlier era, philosophers sometimes suggested that they thought that there is such a thing as 'the feeling of pleasure itself' - as if there were some phenomenally distinct sensation that is 'pleasure itself'. But that view has fallen into disfavor. At least since the time of Sidgwick, hedonists have almost universally agreed that there is no such feeling. As Sidgwick said, '... when I reflect on the notion of pleasure ... the only common quality that I can find in the feelings so designated seems to be that relation to 
desire and volition expressed by the general term 'desirable", ${ }^{2}$ Ryle added a number of further arguments against this so-called 'distinctive feeling view'. 3 Nowadays the dominant view is that what makes a sensation count as a sensory pleasure is not some phenomenally given sensory 'feel'; it is rather that the one who experiences that sensation takes up some attitude toward it. Precisely what attitude is required is a matter of controversy. Some (e.g., Parfit 1984: 493) say it is desire; some (e.g., Sidgwick 1907: 127) say it is believing to be desirable; some (e.g., Brandt 1979: 38) say it is wanting it to continue. I have defended the view that a token sensation counts as a sensory pleasure iff the person who experiences it takes intrinsic attitudinal pleasure in the fact that he himself is then having that sensation. ${ }^{4}$

Any such attitudinal view implies that when a person experiences a sensory pleasure, there are two relevant 'intensities'. Here's a familiar example that illustrates these two intensities nicely: suppose someone is taking a hot shower. ${ }^{5}$ Suppose he is enjoying the feelings of warmth that he gets as the hot soapy water splashes on his body. Then one intensity is the intensity of those feelings of warmth. Presumably, if the water were to become hotter, those feelings would increase in intensity. The other intensity is the intensity of the relevant attitude. On my view, the feelings of warmth count as sensory pleasures because the person experiencing those feelings takes intrinsic attitudinal pleasure in the fact that he himself is then feeling them. The attitude also has some intensity, though this is not a matter of feeling. It is rather like intensity of belief, or of hope, or of other similar attitudes. A person can take more or less pleasure in the fact that he is experiencing some feeling.

In a simple case, the intensity of the sensation and the intensity of the attitude might increase together. Perhaps someone takes more attitudinal pleasure in feelings of warmth as those feelings become more intense. But, as should be clear, the two intensities can vary independently. If the feelings of warmth become too intense, the experiencer may begin to find them less enjoyable. In other words, he may take less intrinsic attitudinal pleasure in the fact that he is feeling them. In this case, the more intense pleasurable feeling becomes less pleasurable.

Ethical hedonism is (roughly) the idea that pleasure is the good. The view can take many forms. In one form, it is the view that a person's life is made better for him by the presence in it of experiences of sensory pleasure. In order to be complete, such a view must contain some principles for evaluating individual sensory pleasures, and other principles for aggregating those values so as to give a value to the life as a whole. (It would also have to contain corresponding principles about pains and their evaluation.) How shall we evaluate an episode of sensory pleasure?

\footnotetext{
${ }^{2}$ Sidgwick (1907: 127).

${ }^{3}$ See, for example, Ryle $(1949,1954$, and 1956)

${ }^{4}$ I first presented this view in Feldman (1988: 59-81); that was reprinted in Feldman (1997a: 79-105). I presented a much more detailed version of the theory in Feldman (2004: B.1). In what follows I shall use my own theory as my example. What I say here about it carries over immediately to any other attitudinal view of pleasure.

${ }^{5}$ I used this example to illustrate the two intensities first in Feldman (1997a: 103) and then more recently in Feldman (2004: 83-85). I characterized the case as seeming 'paradoxical' in both places.
} 
No reasonable advocate of this sort of view maintains that sensory pleasures are more valuable as the sensations themselves become more intense. This would imply, absurdly, that my life is going better for me when the hot water in my shower starts to scald me. The more reasonable view is that a sensory pleasure is more valuable as the relevant attitude becomes more intense. On my version of this view, my sensory pleasure in the hot shower becomes more pleasurable and more valuable as I take greater intrinsic attitudinal pleasure in the fact that I am having that experience. Clearly, then, such a view is not committed to the notion that more intense ple asurable sensations are necessarily better. If the sensations become too intense, they may become less pleasurable and less valuable. It depends upon the intensity of the relevant attitude.

5. Any such version of attitudinal hedonism is consistent with an even more interesting fact: a sensation that starts out being a sensory pleasure can gradually turn into a sensory pain. This could happen, for example, if the feelings of warmth in the hot shower were at first enjoyed and subsequently 'disenjoyed'. The advocate of attitudinal hedonism can say ${ }^{6}$ that a sensation becomes a sensory pain when the person who experiences it starts taking attitudinal pain in the fact that he is feeling it. So if the water becomes too hot so hot that it starts to hurt - then there is a certain sensation that formerly was a sensory pleasure (because the experiencer took attitudinal pleasure in it at that time) and that later became a sensory pain (because the experiencer took attitudinal pain in it at the later time).

This shows that on an attitudinal theory of pleasure and pain, a given sensation's status as a sensory pleasure (or pain) is a contingent and possibly temporary feature of that sensation. While the experiencer has the right attitude toward it, it is a pleasure. Later it may stop being a pleasure and may even start being a pain. Clearly, the advocate of this sort of sensory hedonism will want to say that during times at which the sensation counts as a sensory pain, its occurrence helps to make the experiencer's life worse.

So there is need for care when talking about increases in pleasure. When we say that a token sensation of pleasure has been increased, we might mean that the intensity of the sensation itself has been increased - it is a stronger sensation. Increases of this sort are not necessarily improvements according to attitudinal hedonism. More intense sensations of heat might be less good. On the other hand, when we speak of an increase in a pleasant sensation, we might mean that the intensity of the attitudinal pleasure taken in that sensation has increased. Increases of this sort would always be improvements according to attitudinal hedonism. I am better off (other things being equal) if I take more pleasure in the sensations of heat that I experience while enjoying a hot shower.

6. Timmerman's 'new paradox of hedonism' is that pleasure cannot be the good, since you can't have too much of the human good, but you can have too much pleasure. These claims are now seen to be ambiguous. What is 'too much pleasure'? Does it mean excessively greater intensity of the pleasant sensation? Or does it mean excessively

\footnotetext{
${ }^{6}$ As I did say on pp. 83-5 of Feldman (2004).
} 
greater intensity of the attitudinal pleasure taken in the sensation? On the former interpretation, the argument looks like this:

1a. If ethical hedonism were true, then increased intensity of a pleasant sensation cannot be excessive - any such increase makes your life better.

2a. But increased intensities of a pleasant sensation sometimes are excessive sometimes they do not make your life better.

3a. Therefore, ethical hedonism is not true.

On this reading, premise (1a) is false. Ethical hedonism is consistent with the notion that there could be a sensation that is pleasant at a certain time (because you take attitudinal pleasure in it) but that would become less pleasant if its intensity were increased. Increasing the intensity of a pleasant sensation might make you take less pleasure in it. In that case, such increases in intensity would not make your life better according to attitudinal hedonism. Clearly, you can have too much of a sensation that (formerly) was a good thing. ${ }^{7}$

On the second interpretation, the argument looks like this:

1b. If ethical hedonism were true, then no increase in the amount of attitudinal pleasure taken in a sensation could be excessive - any such increase would make your life better.

2b. But increased amounts of attitudinal pleasure taken in a sensation sometimes are excessive - sometimes they do not make your life better.

3b. Therefore, ethical hedonism is not true.

The advocate of attitudinal hedonism will say that premise ( $2 b)$ is false. If you are more pleased by a certain sensation, it is in this way a greater pleasure and it helps to make your life better. So long as the intensity being increased is the intensity of the attitudinal pleasure you take in the sensation, the increase is guaranteed to improve your life. You can't take too much pleasure in a sensation.

Thus, Timmerman's 'new paradox of hedonism' is neither new nor paradoxical. It presents no difficulty for modern forms of hedonism. ${ }^{8}$

\author{
University of Massachusetts at Amherst \\ Amherst, Massachusetts 01003 USA \\ ffeldman@philos.umass.edu
}

\footnotetext{
${ }^{7}$ Some remarks in his discussion of the third possible reply (2005: 146) suggest that Timmermann might have been aware of this interpretation of his argument. He remarks that it is 'far from certain that the sums would come out right.' I discussed this question in Section 4.2 "Measuring Attitudinal Pleasures and Pains" of Feldman 2004. I tried to show that if we assign the numbers carefully, the sums will come out right (barring some unrelated difficulties discussed later in the book).

8 Thanks for Chris Heathwood and Michael Clark for helpful comments on earlier drafts.
} 


\section{References}

Brandt, R. B. 1979. A Theory of the Good and the Right. Oxford: Clarendon Press.

Feldman, F. 1988. Two questions about Pleasure. In Philosophical Analysis: A Defense by Example. ed. D. S. Austin, 59-81. Dordrecht: Kluwer Academic Publishers. Reprinted in Feldman, (1997a: 82-105).

Feldman, F. 1997a. Utilitarianism, Hedonism, and Desert: Essays in Moral Philosophy. Cambridge: Cambridge University Press.

Feldman, F. 1997b. On the Intrinsic Value of Pleasures. Ethics 107: 448-466. Reprinted in Feldman (1997a: 125-147).

Feldman, F. 2004. Pleasure and the Good Life: Concerning the Nature, Varieties, and Plausibility of Hedonism. Oxford: Clarendon Press.

Parfit, D. 1984. Reasons and Persons. Oxford: Clarendon Press.

Ryle, G. 1949. The Concept of Mind. London: Hutchinson.

Ryle, G. 1954. Pleasure. Proceedings of the Aristotelian Society, supplementary volume 28: 135-146.

Ryle, G. 1956. Dilemmas. Cambridge: Cambridge University Press.

Sidgwick, H. 1907. The Methods of Ethics. $7^{\text {th }}$ ed. London: Macmillan.

Timmermann, J. 2005. Too much of a good thing? Another paradox of hedonism. Analysis 65: 144-46. 